\title{
The Research on the Preventive Strategy of College Suicide Crisis -The Assessment and Implication of a Case of Suicide High-Risk Prevention
}

\author{
Binbin $\mathrm{Li}^{1}$ \\ ${ }^{1}$ College of teacher education, Chongqing University Of Education, Chongqing, 400065, China \\ hunter2011@foxmail.com
}

Keywords: College, Suicide, Crisis Prevention, Work Strategy

\begin{abstract}
Based on a assessment of students suicide prevention with high-risk, this paper tries to explore the implications of the case for suicide crisis prevention work in colleges and universities, and calls for suicide crisis prevention mechanism in universities, establish the prevention strategies of suicide crisis, set up suicide crisis prevention related courses for the teachers and students, establishes mental health education system and crisis classification system, establish schools, homes, hospitals, community comprehensive prevention model for intergovernmental cooperation.
\end{abstract}

\section{Introduction}

In recent years, the number of college students suicides is rising and suicide rate among college students is two to four times than that of their peers [1], leading to many studies. As the submission deadline date, searching the CNKI and finding that the literatures titled with "students" and "Suicide " is up to 971, but literature with" students "," suicide "and" case "is only 11. It is visible that lack of case studies of students suicide crisis prevention or intervention and also lack of research on relationship between college students work and students' suicide [2], the growing number of college campuses suicide cases and suicide-related research is lagging behind has become one of the major difficulties facing the University Mental workers. The occurrence of suicide insufficient understanding of the development process to bring pressure has enlarged consultant anxiety, so that they are more produce collusion with other sectors in schools, simply classified suicide as an impulse irrational behavior, so they can deal with it directly and simply [3]. Therefore, it is necessary for the university to do more work as a reflection and to take effective measures in suicide crisis intervention [4].

Based on a assessment of students suicide prevention with high-risk, this paper tries to explore the implications of the case for suicide crisis prevention work in colleges and universities, and calls for suicide crisis prevention mechanism in universities, establish the prevention strategies of suicide crisis and set up suicide crisis prevention related courses for the teachers and students, establishes mental health education system and crisis classification system, establish schools, homes, hospitals, community comprehensive prevention model for intergovernmental cooperation.

\section{The Case Study}

Perceive and evaluate suicide risk. One day, $Z$ Graduates ask for leave due to a cold and it has not been approved but he decides to go home. When I asked him to provide sick leave, $\mathrm{Z}$ said that going home is to participate in a superstitious ritual to avoiding something bad, because some time ago there is a problem in his body and life. I consciously thought he urged them to return to school interview ignorance, confusion felt when he interviews the next day, describing the grotesque, the suspected presence of hallucinations, insomnia and readme often, there is a profound sense of oppression, meaningless sense of worthlessness, and so there is no sense. I suspect $Z$ had suicidal thoughts, and asked him: "Do you have suicidal thoughts?", $Z$ admitted immediately and said this idea has lasted more than a month; I asked: "Have you thought about how to commit suicide?", Z said 
after a long period of reflection and comparison, there are specific plans. I ask: "In the other stages of your life, whether there had been a similar idea or behavior?" $\mathrm{Z}$ said that in junior high school sophomore and small sixth embodiment respectively over a suicide. At this point, my initial judgment is $\mathrm{Z}$ is at high risk of suicide stage.

Start suicide crisis prevention work. $Z$ is with a high risk of suicide and may be accompanied by mental disorders, I immediately discussed decryption issues with $\mathrm{Z}$, recommends $\mathrm{Z}$ in accompanied by their parents to go to hospital for examination, but in the field to the school their parents will take time, I worried $\mathrm{Z}$ at high risk emotional impulse to commit suicide, asking him to sign a "no suicide undertaking", let self-restraint impulse to commit suicide.

Then, immediately notify the parents and invited back to Chongqing. I have repeatedly explained its danger $\mathrm{Z}$ still refused, until the condition advertised $\mathrm{Z}$ may affect the smooth graduation, his mother reluctantly agreed to the school over a period of time. Since the urgency of the situation, I had to turn to $\mathrm{Z}$ of available resources, to decrypt two roommates and signed a "entrusted with the care agreement" with them, a 24-hour companionship and interventions $Z$.

A few days later his mother take $Z$ to the hospital, the hospital requires hospitalized for a week to observe, $\mathrm{Z}$ is very inconsistent, barely two days in hospital and diagnostic results not so they insisted was discharged, the hospital had allowed. I want to return to school after discharge $Z$ learning, the school should not be considered at this school learn Z, Z recommendation mother to go through the formalities leave home recuperating, students heard the news very angry and refused to go home to recuperate. School had renegotiated intervention programs, because Z would like work-study, psychological center just to have jobs available to him, the center of the teacher asked him to report on time every day, in order to grasp the Z's life and whereabouts, this arrangement is satisfactory Z. At this point, the counselors, roommates, psychological crisis intervention center teachers from suicide together, take turns to accompany, jointly prevent, safely through the dangerous period and his graduate.

\section{The Case Evaluation}

From a personal point of view and a short, a perspective of a crisis intervention-oriented point of view, the case of the $\mathrm{Z}$ implement successful prevention of suicide, used to assess the degree of risk, decisive intervention, immediate assistance precautions. Paper [5] showed that these measures can indeed reduce suicide, but suicide is not only a personal problem, but also social problems, because suicide brought incalculable consequences, in their own lives may be lost, but also devastating to the family blow to the surrounding classmates, friends and teachers bring psychological shadows and trauma. Therefore, if from the point of view of social problems and long-term, growth-oriented suicide prevention perspective, case processing still has room for improvement.

Identifying suicide warning and assessing suicide risk ASAP is the key point of successful prevention assurance and premise. Study [5] pointed out, when someone with suicidal tendencies, should pay attention to three things: listen, assess and find help. One of the most important suicide prevention strategy is before students attempt suicide, have been able to confirm the warning signs of suicide, such as tried to commit suicide, an oral statement to the end of his life, suicidal plan, recently encountered serious problems and other things. To commit suicide intervention must involve assessment, in a safe situation, teachers and other relevant personnel application calm, direct, caring and understanding attitude willing to ask students about the suicide plan, and to promptly assess the nature and severity of suicidal behavior, You must be directly asked the students: have you ever thought of suicide; there is no definite plan to commit suicide; condition plan ready if needed; whether the plan will result in death or serious injury; if determined to carry out his plan.

In summary, in this case, I did it in advance to confirm the warning signs of suicide - verbal recognition to end their lives, tried to commit suicide, suicide plan. After confirming signs and assessment process can calmly listened carefully, and calm, direct, care to ask their suicide plan of action, orderly and layers of depth and asked: Have you ever thought of suicide; there is no definite 
plan to commit suicide; have you ever tried to commit suicide, etc., so it can quickly identify suicidal tendencies and risk assessment, carried out a suicide crisis intervention provides a basis in advance.

Intervene decisively but can still lift. People in high crisis situation may erratic and impulsive, teachers quickly decided and bold action is even more important [5]. In this case, the active intervention of consciousness reflected significantly, has taken to sign a "no suicide undertaking" organization "suicide prevention pickets" referral hospitals and other measures to prevent the success of student suicide, but in the long and growing cases perspective, each intervention sectors still room for improvement.

The work of inform parents needs to enhance, strengthen home-school relations and cooperation. When students have suicidal crisis, informed parents are a must, although parents may have a variety of reactions attitude, rather than a more cooperative attitude will increase the difficulty of crisis, so the school dilemma. But schools cannot be in accordance with the wishes of the parents never who cooperate without regard to the student being troubled. Even if parents oppose, teachers must take immediate and decisive action to, to protect students and prevent them from any self-destructive behavior. In the process of informing the parents, if the parents refused to do in accordance with the recommendation of the school, informing them of the school will notify the relevant government departments; others permit in advance to inform students and parents to participate in all or part of the talks [5].

In this case, we did notify parents immediately, but did not get the understanding and support of parents, even so, the school still insists on providing assistance to students to ensure their safety. But in the latter's talks with parents, whether the parents are not informed in advance permit students to participate in the talks, so that the parents stand shaken, not persuade children to actively check or pay attention to rest, and let the child's impulse to mercy, but alienate the relationship between students and schools Students therefore more conflict with school actions, so that the things that dilemma, therefore, should be informed in advance whether to grant the parents of students involved in all the talks, which is the case need to upgrade the place.

From the "Do not commit suicide commitment" to "no suicide contract", the wording and content required to upgrade. When the suicide crisis, the main purpose of counseling is to help students control their impulses emotions, for which teachers can use "no suicide contract" or "Do not hurt yourself protocol" to encourage students to self-discipline its suicidal behavior, which is to reduce risks and A way to prevent suicide counseling increased degree of safety. As for the timing of the signing, the student cannot promise his family when hospitalized for observation; or student after receiving crisis counseling for suicide have a more correct concept; or the case is still stable, counselors think they have sufficient capacity to support him through the crisis. The agreement is designed to help students control their impulse to commit suicide, rather than simply alleviate the concerns of teachers and avoid responsibility; shall include such consent not to try to commit suicide, there will be plenty of sleep and eating enough food, throw away all the available Items for suicide, Lie Mingqi about the deadline, if he intends to breach of contract or try to commit suicide, he must call to a counselor or a suicide prevention hotline, wrote need to contact the phone, only to feel the crisis if the contact; a systematic column Ming how to pass the time as talking, watching movies, shopping, etc. [5].

Case, when his family has not been to school and $\mathrm{Z}$ unwilling hospitalized for observation, I asked $\mathrm{Z}$ signed a "no suicide undertaking", the time is more appropriate, self-discipline which also reached the purpose suicidal behavior. However, the wording "not suicide undertaking" might have avoided the suspicion of responsibility, which could damage the relationship between teachers and relief properties. From the content point of view: "I promise *** now, when their actions do not do any harm to the hospital before, if once suicidal, self-injury or self-mutilation and other thoughts, before taking action, first teacher and contact counselor *** ", where" prior contact before the implementation of suicidal behavior counselors' convention to establish a channel for the $\mathrm{Z}$ and psychological security services immediately, but less comprehensive protocol measures, increase the "throw away the tool, lists the system to pass the time providing suicide prevention hotline telephone ", to better ensure the safety of students. 
From the "entrusted with the care agreement" to "Suicide Prevention pickets," naming and the mandatory need to increased. When signs of suicide, parents and teachers are necessary to immediately find a helper, a teacher has no responsibility to provide all the treatment services. If for any reason the student cannot be admitted temporary, but the results of the assessment is a high-risk, counselors should seek to organize "Suicide Prevention pickets" custody are at high risk situations for students, prevent him from suicide. Although counselors cannot provide close supervision, but there is still responsible for arranging and ensuring the maintenance of a 24-hour surveillance, the need to master and each case can picket 24 hours contact phone number. If the family is difficult to become a picket, friend or neighbor can also enable other a helping hand as pickets, pickets must accept all instruction, whether it is eating, sleeping, walking, etc. should remain in the student side [5].

In this case due to insufficient cooperation family, I turned to $\mathrm{Z}$ around available resources, to decrypt two roommates and signed with them, "entrusted with the care agreement", "this commission *** and $*^{* *}$ as 24-hour companionship and to $\mathrm{Z}$ interventions to prevent it going out alone, remove it dangerous tools around, when you cannot control the situation promptly notify the counselor ", which is actually in the organization" suicide Prevention pickets ", accompanied by an excellent two roommates to prevent the $\mathrm{Z}$ implementation suicide, suicide prevention counselor share the pressure, but the agreement and the need to increase mandatory. $Z$ refusal home recuperating after discharge, the face of unexpected circumstances Schools reassess their risk, relying on psychological center expansion of the "suicide prevention pickets", then, mental health education center responsible for contact with $\mathrm{Z}$ and $\mathrm{Z}$ learning counselor responsible for oversight, roommates responsible for their lives, accompanied by the three parties together to successfully implement suicide prevention $Z$.

The need and regret for hospitalization [5] It was believed that suicidal behavior of people need hospital treatment, medical staff in the hospital for monitoring, accessible 24 hours non-stop access to treatment, while reducing the chance of suicide increased personal security, allowing the parties a speedy recovery and will reduce death to a minimum. The ideal approach is to convince students to voluntary admission, followed forced him to consider admission. After admission, the teacher still in close contact with the students, so that students feel forgotten, isolated or sell. Teachers should be involved in hospital discharge meeting and asked the hospital to provide post-processing in school.

In this case, the school had tried to persuade the parents to accompany $\mathrm{Z}$ go to the hospital or treatment, but strong resistance and self- $Z$ discharged early, and the school has not been invited to participate in the hospital's discharge decision, but according to the current domestic situation is difficult to force students to school admission, also difficult to have the opportunity to provide 24-hour surveillance of cases and treatment, and finally, the school can only assume this responsibility, increasing the difficulty and insecurity suicide crisis prevention.

The need and regret for professional psychological assistance. If students have any warning signs of suicide, parents and teachers should immediately seek psychologists, psychiatrists and other professionals. Even if teachers can successfully open and frank communication with the students, we cannot bear all the responsibility. Family and friends can help people with suicidal behavior, but their involvement may not be able to solve problems. As the parties are deep into the high crisis, only psychologists and psychiatrists to assess the severity of the crisis and provide suicide prevention treatment and action suicidal behavior [5].

In this case, the counselor alone to bear too much responsibility and pressure to intervene, because the professional capacity, dual relationship and effort restrictions, cannot provide adequate psychological assistance to Z, also did not take it to seek other professional psychological assistance, therefore, from the case long-term development, in this case the individual cases in enhancing capacity and increase protective factors failed to conduct sufficient exploration, indeed regrettable. 


\section{The School Policy of the College Suicide Crisis Prevention Work}

In summary, although the case of successful interventions student to commit suicide, but because schools lack the suicide crisis prevention mechanism, when the suicide crisis comes, can only rely on the professional judgment of individual resilience and temporary staff, when there is not easy to be in uncontrollable factors cases of manipulation or passive state, is not conducive to long-term growth crisis intervention work smoothly and cases. Therefore, the university should be a pre-established suicide crisis intervention mechanism, improve the work of a suicide crisis prevention school policy from the following aspects.

Set up related courses of suicide crisis prevention and preventive measures. Teachers set up suicide crisis intervention training courses to help teachers learn to recognize the warning signs of suicide before, to clarify its understanding of suicide in the face of fear and pressure to ease its case when a suicide crisis, enhancing their courage and confidence, and then train the suicide crisis the basic attitude of prevention, principles and strategies.

Set up life education and suicide prevention education program for the student. Life education classes stimulate students cherish life, to explore the meaning of life, encourage students to face difficulties courage and confidence, attention to the development of students' personal resources, the use of family peer resources to enhance the quality of life of college students; suicide prevention education classes church classmates identify warning signs of suicide before and encourage mutual concern among students and found that timely reporting in crisis situations, and jointly safeguard the lives and safety of themselves and the students around.

Establish mental health systems and crisis classification systems, making division of labor in the institutions. Suicide prevention efforts need professional psychological assistance, but there is general lack of teacher resources Mental Health, Department counselor often being in the front line suicide crisis prevention, due to lack of professional training or have reason dual relationships, etc., is difficult to effectively expand Suicide prevention work. Teachers in the Department of Mental Health to establish the system, that every mental health crisis intervention teacher counterparts corresponding faculty guidance, both to solve the problem of teacher resources, and easy to implement the human responsibility, division of labor, stress decomposition, effective intervention.

In the establishment of the Mental Health Department of the system, at the same time, the establishment of a suicide crisis classification system, by professional teachers assess crisis levels, according to the degree of risk from low to high can be divided into suicidal ideation, suicide attempts and suicide by [6], the different levels Case distinction crisis treatment. Such as suicidal ideation are in need of psychological counseling; suicide attempts except those in need of psychological assistance, the need to track a family member or counselor to accompany faculty; and suicide need urgent intervention, the formation of "Suicide Prevention pickets" or implement prevention hospitalized again suicide, or suicide after the completion of the post-intervention for trauma associated personnel for psychological counseling.

The establishment of comprehensive prevention model of community cooperation of schools, homes, hospitals and government, commonly preventing suicide. Suicide prevention is an extremely complex task alone personal or school handedly difficult to complete, and only the whole society work together, can we identify danger signs early and accurate assessment, decisive intervention, effective measures such as immediate assistance smoothly. It calls for schools, families, hospitals and social to cooperation with the government of comprehensive prevention mode, each power should perform their duties, complementary advantages, mutual support for suicide prevention crisis. Development of relevant government policies and regulatory enforcement suicide intervention, hospital or specialized agencies make assess, hospitalization or intervention strategies, school faculty with professional bodies should be responsible for contacting family resources, family is responsible for providing companionship and guardianship. Thus, a plurality of channels multifaceted cooperation starts suicide crisis intervention from the perspective of long-term, to ensure the safety and quality of life of college students. 


\section{References}

[1] T. Zhu. Students Suicide Prevention and Crisis Intervention Strategy. Zhejiang Normal University Master Degree Thesis, 2011: 1.

[2] H. Yu, L.C. Yang, K.R. Lu. Summary of Suicide Study Students. Shandong Teenagers Politics College, 2011, 06: 56-61.

[3] Y. Cai. The Understandable Suicide-Case of College Students Psychodynamic Interpretation. Nanjing Medical University (Social Science Edition), 2015, No. 3, 247-250.

[4] X. Chen. Students Suicide Intervention Strategies based on the Perspective of College Students Work. Fujian Normal School Master Thesis, 2013: III.

[5] Y.L. Xie. Suicide Awareness, Prevention and Crisis Management of Young People. Chinese University of Hong Kong Press, 2000 First Edition: 5-239.

[6] R. Du, G.R. Jiang. Suicidal Behavior: Factors, Theoretical Models and Research Prospects. Advances in Psychological Science, 2015 (23), 8, 1437-1452. 